\title{
Applications of shear heating parameter for injection molding process optimization of AEM rubber compounds
}

\author{
Mattia Ramini $^{1,2^{*}}$, Silvia Agnelli ${ }^{2(\mathbb{D})}$, Giorgio Ramorino ${ }^{2(1)}$ \\ ${ }^{1}$ Italian Gasket S.P.A., Via Tengattini N.9, 25030 Paratico (Bs), Italy \\ ${ }^{2}$ University of Brescia, Department of Mechanical and Industrial Engineering, Via Branze 38, 25123 Brescia (Bs), Italy
}

Received 19 July 2021; accepted in revised form 13 November 2021

\begin{abstract}
Shear heating phenomena during injection molding of rubber compounds greatly affect product quality but are difficult to control and replicate with laboratory tests. In this work, a very fast online process control of industrial injection molding is proposed, based on the measurement of surface temperature by infrared thermal camera of the rubber as it leaves the extruder barrel. Moreover, a new technological parameter (shear heating parameter, $\eta_{\mathrm{SH}}$ ) is calculated from the measured temperature. A robust correlation between $\eta_{\mathrm{SH}}$ and viscosity from rheometric laboratory measurements was achieved for different rubber compounds. This represents an operating roadmap to support the process engineer in the improvement of process control. To show the potential of this tool, it was successfully used to optimize the injection molding of industrial production of AEM rubber compound affected by scorching and thermal degradation issues. $\eta_{\mathrm{SH}}$ was found to be suitable for industrial practice and able to provide accurate information about thermal history and process safety.
\end{abstract}

Keywords: industrial applications, processing technologies, rubber, AEM rubber, shear heating

\section{Introduction}

Nowadays, the automotive industry requires rubber parts of very high quality. Therefore, it is advisable to improve control of the injection molding process, especially in the machine. Injection molding is one of the most commonly used rubber processing technologies enabling the manufacture of final products [1]. The quality of the final product is the result of a combination of factors, including the rubber, mold design, the process, and injection molding machine capability. Consequently, rubber processing by injection molding is very complex and influenced by several parameters, such as temperature, pressure, and shear rate. One of the most important control parameters is temperature. Even though the mold temperature is very easy to control by using thermocouples or other in-mold sensors, on the contrary, the rubber temperature is very difficult to control because it varies according to parameters such as injection pressure, injection speed and screw rotation speed. In particular, the rubber temperature is not only critical for the curing stage but also for the filling stage. If the rubber temperature increases too much, it can start to cure during cavity filling, which can generate defects in the molded parts with possible elongation decrease because the cure progressed too quickly, causing scorch [2]. On the other hand, if the curing reaction occurs while rubber is flowing, viscosity increases sharply, and flow will virtually stop, so that some areas of the mold may not fill properly. Therefore, the mold cavity should be filled completely with rubber before curing commences $[2,3]$. Nevertheless, it will be important to guarantee a suitable rubber temperature, a compromise between scorch safety and cure commencing, to improve the cycle time and productivity. When rubber flows too fast into one

\footnotetext{
${ }^{*}$ Corresponding author, e-mail: m.ramini@unibs.it
} (C) BME-PT 
specific cavity, faster than the cavity immediately beside it, there is a shear rate difference. The higher the shear rate, the greater the shear heating and the larger the effect on viscosity. The problem is that the viscosity is not affected uniformly everywhere, but it is only affected in the material at the higher shear rate, whereas the lower viscosity rubber flows more easily under pressure and a filling imbalance is created [2]. Other molding problems due to rubber temperature being too high are mold fouling and sticking phenomena, mainly due to diffusion of rubber compound ingredients [4].

Furthermore, the shrinkage in the parallel direction is larger than in the perpendicular direction, and anisotropic shrinkage increases with the increase of vulcanization temperature and flow distance. The shrinkage is independent of the 'expanded orientation' (i.e., macromolecular orientation due to material thermal expansion and perpendicular to rubber flow), but is strongly associated with the shear orientation, while the mechanical properties are affected by the expanded orientation [5].

Three main sources of heat can increase the rubber temperature in the injection molding process: the heating system of the machine, the exothermal curing reaction, and shear heating. The last factor is a phenomenon where internal friction within the rubber, while it is flowing, generates heat and locally reduces the viscosity [1-12]. This phenomenon is often present in the industrial processing of rubbers and, although it is advantageous to increase the temperature of the rubber by saving energy, it complicates the control of the temperature and also of the viscosity [4].

In this article, the processing behavior of ethylene acrylate rubber (AEM) by injection molding is investigated, with a focus on scorch and thermal degradation issues. Ethylene acrylate elastomers were first introduced to the market more than 40 years ago. They are non-crystalline copolymers of ethylene and methyl acrylate. Both monomers are responsible for giving high-temperature stability and the completely saturated polymer chains that impart excellent resistance to ozone, oxidation, and weathering. The nonpolar ethylene contributes to the good low-temperature flexibility. Most of the polymer grades contain a small amount of acidic cure site monomer for diamine crosslinking, while the polar methyl acrylate monomer provides the oil and fluid resistance. Since its introduction by DuPont under the trade name
$\operatorname{Vamac}^{\circledR}$ in 1975, it has been used in the automotive industry, in particular, for example, for turbocharger hoses, transmission oil cooler hoses, positive crankcase ventilation hoses, and exhaust gas recovery hoses. Furthermore, AEM is a suitable material for seals and gaskets for automatic transmissions and engines [13-16].

A high percentage of AEM parts used in the automotive industry are made from AEM terpolymer compounds cured with diamines. As reported in literature works by McBride from DuPont [13-15], these compounds are more prone to scorch than most elastomeric compounds; thus, suitable process control has to be provided in order to prevent it. The diamine curative reacts with the cure site monomer in a twostep curing process: the first step involves the formation of an amide (relatively fast step, which occurs in the mold); the second step involves the conversion of the amide to an imide (this reaction is slow and requires a long post-cure step to finish the cure, usually 4 hours at $175^{\circ} \mathrm{C}$ ). After the injection molding process, the part has dimensional stability, but the compression set is high (70 to $90 \%$ after one week at $150{ }^{\circ} \mathrm{C}$ ), and the hardness and modulus are relatively low. The post-cure stage increases the hardness until the required specification is met, and the compression set drops to about $20-30 \%$.

The first step is the source of the scorch. Scorch issues can cause molding problems such as underfilling the mold cavity and problems at knit lines, which necessitate extra processing aids to lower viscosity. Scorch reactions are a function of time and temperature, and they become an issue for AEM compounds at temperatures above $100^{\circ} \mathrm{C}$. Therefore, for AEM compounds, the processing temperatures (mixing, molding and/or extrusion) should be kept under $100^{\circ} \mathrm{C}[13-15]$, which is very difficult to maintain, for instance, in the injection molding machine extruder due to shear heating. However, as the temperature further increases, there will be a point at which the viscosity starts to increase due to the scorching of the compound. Furthermore, in the worst cases, if the rubber temperature increases too much due to higher shear rates, thermal degradation by loss of plasticizer and processing aids can start.

An optimal rubber temperature must ensure a balance between not having excessively high viscosity, scorch safety, and thermal degradation. The actual rubber temperature in an injection molding machine, mostly generated by shear heating, is very difficult 
to replicate in the laboratory by typical instruments such as a moving die rheometer (MDR), because the MDR does not reproduce properly the physical process occurring in the injection stage of the molding machine extruder. The shear heating generated inside the injection molding machine extruder depends on the screw length to diameter ratio $L / D$, and mostly on the process parameter setup, such as screw rotation speed, injection pressure, speed and time, barrel temperature setup and other factors [4, 17].

This work puts forward an approach to improve the control of industrial injection molding of technical rubber parts based on the measurement of rubber temperature. The approach is based on very fast online process control, which is suggested in order to be used in industrial practice, and consists of the direct measurement of rubber surface temperature $\left(T_{\mathrm{SH}}\right)$ by the infrared thermal camera at the nozzle outlet of the injection molding machine extruder. Although the temperature of the rubber leaving the extruder is not homogeneous, it can be more conservative in measuring the rubber temperature on the surface where the temperature is higher (according to shear-thinning theory) [3]. The use of an infrared thermal camera does not disturb the rubber flow and is a noncontact method characterized by a very fast response $[4,11,18-20]$. The measured rubber shear heating temperature $\left(T_{\mathrm{SH}}\right)$ is then used to calculate a technological parameter designated shear heating parameter and labeled $\eta_{\mathrm{SH}}$. The results of $\eta_{\mathrm{SH}}$ were compared with minimum torque, $M_{\mathrm{L}}$, from MDR routine rheometric laboratory measurements for eight different industrial rubber compounds, based on AEM, hydrogenated acrylonitrile butadiene rubber (HNBR), fluorocarbon rubber (FKM) and ethylene-propylene-diene monomer rubber (EP(D)M). The measured $M_{\mathrm{L}}$ value is a rough indication of the rubber compound viscosity; hence variations of $M_{\mathrm{L}}$ affect the rubber processability. Instead, the calculated $\eta_{\mathrm{SH}}$ value combines both rubber composition and operating condition effects, giving more information about the thermal history of the rubber injection stage and process safety [4].

A robust correlation between $\eta_{\mathrm{SH}}$ and $M_{\mathrm{L}}$, labeled roadmap, was sought and is shown in this work by considering various rubber compounds having different elastomeric matrices, AEM, HNBR, FKM, and $\mathrm{EP}(\mathrm{D}) \mathrm{M}$, different geometries of the molded parts (both O-rings and technical rubber items), and also different injection molding machines and process parameter setups. This heterogeneous pattern of rubber compounds was chosen to develop a phenomenological approach based on a robust roadmap, with the purpose of supporting the process engineer in the improvement of process control by thermal online measurements [4, 11, 21-23]. To show its potential, this work shows how this roadmap can be successfully used to improve the process control of AEM rubber compound industrial production affected by scorch problems and thermal degradation due to plasticizer loss [24].

\section{Theoretical background}

Starting from the online measured shear heating temperature $\left(T_{\mathrm{SH}}\right)$ of the rubber, the shear heating parameter, $\eta_{\mathrm{SH}}$, is calculated according to the Equation (1) [4]:

$\eta_{\mathrm{SH}}=\Delta T_{\mathrm{SH}} \frac{\rho C_{\mathrm{p}}}{4 v} \alpha$

where $\Delta T_{\mathrm{SH}}\left[{ }^{\circ} \mathrm{C}\right]$ is the temperature difference between $T_{\mathrm{SH}}$ and the initial temperature (considering $20^{\circ} \mathrm{C}$ as initial temperature), $\rho$ is the rubber density $\left[\mathrm{kg} / \mathrm{m}^{3}\right], C_{\mathrm{p}}$ is the specific heat capacity $[\mathrm{J} / \mathrm{kg} / \mathrm{K}]$, $v\left[\mathrm{~s}^{-1}\right]$ is a flow rate parameter, and $\alpha$ is a function of process parameters such as $D / L$, screw rotation speed, injection pressure, speed and time, barrel temperature setup and other factors. Due to the complexity of the injection molding process, a thorough investigation needs to be performed to define $\alpha$ and its dependence on the process parameters. However, in this work, $\alpha$ is approximated as equal to $D / L$ because, according to experimental data (not yet published), it is one of the most relevant factors contributing to shear heating during the injection stage. Therefore, $\eta_{\mathrm{SH}}$ is a technological parameter having dimensions of viscosity [Pa·s] [4].

Equation (1) is inspired by the equation reported below, where the temperature rise $(\Delta T,[\mathrm{~K}])$ due to shear heating of rubber in an extruder is related to rubber viscosity $[4,6]$ (Equation (2)):

$$
\Delta T=\eta \frac{4 \dot{\gamma} L}{\rho C_{\mathrm{p}} D}
$$

Equation (2) is derived for a simple cylindrical channel, a tube with dimensions $L$ (length) and $D$ (diameter), where a Newtonian fluid is flowing with a stationary laminar flow with $\dot{\gamma}$ as wall shear rate, 
therefore, assumptions such as no wall slip, Newtonian fluid, and adiabatic flow (no heat transfer to the surroundings) were considered [8].

The authors are aware that most of these assumptions do not apply to rubber. Nevertheless, they were inspired by Equation (2) to derive the technological parameter $\eta_{\mathrm{SH}}$ in Equation (1), which is proposed with the purpose of providing a suitable process parameter setup during the injection phase [4].

\section{Experimental}

Eight different rubber compounds were investigated: two EP(D)Ms, one sulfur and one peroxide cured, three AEM rubbers, all diamine cured, two HNBR, both diamines cured, and one FKM, peroxide cured. These industrial-grade rubber compounds were developed in accordance with automotive industry standard specifications, and their formulations cannot be disclosed for confidentiality reasons. They are characterized by $60 \pm 5$ Shore A hardness according to ASTM D2240-15, and by a filler type and content according to available International Material Data System (IMDS) data, as reported in Table 1. The black filler was usually carbon black type N 990 . Black and white filled rubber compounds were characterized by both laboratory tests and processing injection trials in the molding machine during daily production runs.

\subsection{Materials}

The eight rubber compounds investigated were the following:

- PO-EPDM-black: peroxide cured and black colored EP(D)M,

- S-EPDM-black: sulfur cured and black colored $\mathrm{EP}(\mathrm{D}) \mathrm{M}$,

- Two types of DIA-AEM-black: diamine cured and black colored AEM,

Table 1. Filler content according to IMDS data.

\begin{tabular}{|l|c|c|l|}
\hline \multicolumn{1}{|c|}{ Rubber } & $\begin{array}{c}\text { Hardness } \\
{[\text { [Shore A] }}\end{array}$ & $\begin{array}{c}\text { Fillers content } \\
{[\mathbf{w t} \% \mathbf{]}}\end{array}$ & \multicolumn{1}{|c|}{ Filler type } \\
\hline PO-EPDM-Black & $60 \pm 5$ & $28.0-33.0$ & Carbon black \\
\hline S-EPDM-Black & $60 \pm 5$ & $26.3-33.5$ & Carbon black \\
\hline DIA-AEM-Black & $60 \pm 5$ & $40.0-46.0$ & Carbon black \\
\hline DIA-AEM-Black & $60 \pm 5$ & $35.0-45.0$ & Carbon black \\
\hline DIA-AEM-Brown & $60 \pm 5$ & $38.0-46.0$ & Silicon dioxide \\
\hline DIA-HNBR-Black & $60 \pm 5$ & $44.5-48.5$ & Carbon black \\
\hline DIA-HNBR-Red & $60 \pm 5$ & $40.0-48.0$ & Calcined kaolin \\
\hline PO-FKM-Green & $60 \pm 5$ & $18.0-23.0$ & Barium sulfate \\
\hline
\end{tabular}

- DIA-AEM-brown: diamine cured and brown colored AEM,

- DIA-HNBR-black: diamine cured and black colored HNBR,

- DIA-HNBR-red: diamine cured and red-colored HNBR,

- PO-FKM-green: peroxide cured and green-colored FKM.

\subsection{Laboratory characterization}

The eight rubber compounds were characterized by using uncured and cured standard samples and the equipment located in the R\&D laboratory of Italian Gasket (Italian plant). The laboratory results collected for each rubber compound were used to calculate the corresponding shear heating parameter $\left(\eta_{\mathrm{SH}}\right)$ by Equation (1), then correlated with minimum torque $M_{\mathrm{L}}$ results.

The uncured samples were used to measure the minimum torque $M_{\mathrm{L}}$ data by an MDR 2000 from Alpha Technologies (Cinisello Balsamo, MI - Italy).according to ASTM D5289-95 at a frequency of $1.7 \mathrm{~Hz}$ and $3^{\circ}$ oscillation amplitude. The vulcanization curve of each rubber compound was measured for $12 \mathrm{~min}$ utes at $177^{\circ} \mathrm{C}$ because this is a historical and wellestablished internal methodology. The Monsanto MDR usually has $350^{\circ} \mathrm{F}$ as the test temperature, corresponding to $177^{\circ} \mathrm{C}$. Moreover, this temperature can be easily reached in an injection molding machine to achieve the cure of a rubber compound.

A laboratory compression molding press from Gibitre Instruments $\operatorname{Srl}$ (Bergamo, BG - Italy) was used to mold $200 \times 200 \times 2 \mathrm{~mm}$ slabs. After 24 hours of stabilization, the cured standard samples were used for density $(\rho)$ measurements, performed at room temperature, by a digital densimeter from Doss (For Lab Italia, Stezzano, BG - Italy) (accuracy: $0.001 \mathrm{~g}$ ) in accordance with ASTM D297-15. The density value to be used for Equation (1) should be measured at the temperature and pressure in the injection molding machine extruder. However, to use an applicable industrial method, the density at room temperature and pressure was considered to be a reasonable approximation of density at higher temperature and pressure. This approximation is supported by the rubber material data reported in the $\mathrm{CAE}$ simulation software database, where a typical density variation is $5 \%$ with temperature increase from $R T$ to $100^{\circ} \mathrm{C}$ and pressure increase from 0 to $200 \mathrm{MPa}$. 
Moreover, the cured samples were used for specific heat capacity $\left(C_{\mathrm{p}}\right)$ measurements by differential scanning calorimetry (DSC) in a 214 Polyma from NETZSCH Geraetebau GmbH (Selb - Germany). The $C_{\mathrm{p}}$ results were recorded from 45 to $245^{\circ} \mathrm{C}$ with a heating rate of $20^{\circ} \mathrm{C} / \mathrm{min}$ and referring to $A S T M$ E1269-11(2018).

DSC was also used to measure the $T_{\mathrm{g}}$ of AEM parts, both $\mathrm{OK}$ and $\mathrm{KO}$ (cracked), recording the first and the second heating from -80 to $40^{\circ} \mathrm{C}$ with a heating rate of $10^{\circ} \mathrm{C} / \mathrm{min}$ and referring to $A S T M$ D3418-21. AEM parts, both OK and KO (cracked), were used to qualitatively analyze their specific IR absorption frequencies by total reflection-Fourier transform infrared (ATR-FTIR) spectroscopy, using an ALPHA II FT-IR spectrometer from Bruker Italia Srl (Milano, MI - Italy) equipped with a Ge ATR crystal. The sample measurements were run at a resolution of $4 \mathrm{~cm}^{-1}$ and applied 24 scans from 400 to $4000 \mathrm{~cm}^{-1}$. Furthermore, AEM parts, both OK and KO (cracked), were used to quantitatively analyze their composition (e.g., elastomers, plasticizers, and fillers) by thermogravimetric analysis (TGA), using a TG 209 F3 Tarsus ${ }^{\circledR}$ from Netzsch Geraetebau GmbH (Selb - Germany). The sample measurements were run in an $\mathrm{N}_{2}$ atmosphere heating from $R T$ to $600^{\circ} \mathrm{C}$ at $20^{\circ} \mathrm{C} / \mathrm{min}$, cooling from 600 to $400^{\circ} \mathrm{C}$ at $40^{\circ} \mathrm{C} / \mathrm{min}$, holding for 2 minutes at $400^{\circ} \mathrm{C}$, then heating from 600 to $850^{\circ} \mathrm{C}$ at $20^{\circ} \mathrm{C} / \mathrm{min}$ in an oxygen atmosphere and holding for 5 minutes at $850^{\circ} \mathrm{C}$.

\subsection{Processing characterization}

The processing injection tests were performed using horizontal injection molding machines located in the Italian plant of Italian Gasket. Five horizontal injection molding machines were selected for the processing investigation.

A 190 Ton MIR from IMG Srl (Capriano del Colle, BS - Italy) with reciprocating screw, $L / D$ ratio of about 15 , was used to produce sealing rings based on DIA-AEM-brown. A 190 Ton MIR with reciprocating screw, $L / D$ ratio of about 16 , was used to produce technical rubber items based on DIA-AEMblack. Another 190 Ton MIR with reciprocating screw, $L / D$ ratio of about 18 , was used to produce intake manifold gaskets based on DIA-HNBR-black and DIA-HNBR-red.

A 300 Ton Engel from Engel Austria GmbH (Schwertberg - Austria), with First In First Out (FIFO) screw, $L / D$ ratio of about 6 , was used to produce O-rings based on another DIA-AEM-black, and two different frame gaskets based on PO-EPDM-black and POFKM-green, respectively.

A 450 Ton IMG from IMG Srl (Capriano del Colle, BS - Italy), with FIFO screw, $L / D$ ratio of about 12 , was used to produce bellows based on S-EPDMblack.

Daily production runs of each rubber compound were investigated and, after the start-up stage, the thermal control tests were performed. Figure 1 shows the online monitoring scheme of rubber surface temperature control.

The thermal measurement for each rubber compound and respective production run was performed every hour, three measures at each time, in order to control the shear heating effect during the injection stage. A thermal imaging camera, Diacam C.A 1882, Chauvin Arnoux Group (Asnières-sur-Seine - France) $\left( \pm 2{ }^{\circ} \mathrm{C}\right.$ accuracy and $0.08^{\circ} \mathrm{C}$ thermal sensitivity), was used to control rubber surface temperature at the

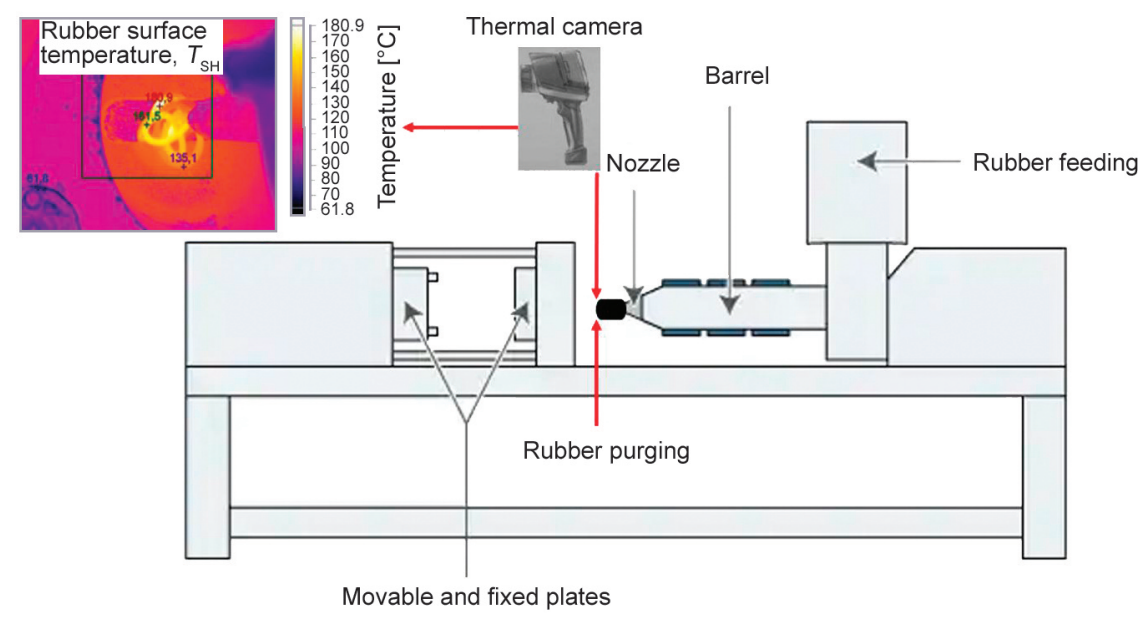

Figure 1. Online monitoring scheme of rubber surface temperature control. 
screw nozzle outlet of the injection molding machine extruder. The infrared thermal camera was used to measure the temperature of the rubber by detecting the emitted electromagnetic radiation. The rubber emissivity was set to 0.95 in accordance with the software material database, and image analysis was provided by the software tools. The advantage of using a commercial brand is to improve the availability of the technology in the rubber industry.

The molded parts, after stabilization, deburring, postcure (if required), and final controls were used as gaskets in the automotive industry.

\section{Results and discussion}

Table 2 reports the setup of the most important process parameters and the summary of average experimental data from both laboratory and injection molding process characterizations for each rubber compound investigated and their respective daily production runs (average data).

Therefore, eight rubber compounds and eight industrial production runs with long process stability, without significant deviations of set parameters and with very little scrap were investigated. Table 2 also reports the results of the investigation of various production runs of DIA-AEM-black: both a very stable production run and an unstable production run are reported, designated DIA-AEM-black-OK and DIAAEM-black-KO, respectively. In addition, the intermediate production runs necessary to restore the process stability are reported and designated DIAAEM-black-INT1 and DIA-AEM-black-INT2, respectively.

Process parameter setup common to all the systems investigated was: injection speed of $70 \%$, the screw rotation speed of $80 \mathrm{rpm}$, injection time of $10 \mathrm{~s}$, cure time of $85 \mathrm{~s}$, barrel temperature of $75 \pm 5^{\circ} \mathrm{C}$, and both fixed and movable plate temperature of $195 \pm 5^{\circ} \mathrm{C}$. $L /$ D ratio of the five injection molding machines used for the processing trials and barrel temperature setup $\left(T_{\text {Barrel }}\right)$ are reported in Table 2 for each system. About laboratory characterization, the data of density $(\rho)$, specific heat capacity $\left(C_{\mathrm{p}}\right)$, and minimum torque $\left(M_{\mathrm{L}}\right)$ at $177^{\circ} \mathrm{C}$ are reported. Finally, the processing characterization data, such as measured shear heating temperature $\left(T_{\mathrm{SH}}\right)$ of the rubber by infrared thermal camera, the temperature difference in shear heating $\left(\Delta T_{\mathrm{SH}}\right)$ considering $20^{\circ} \mathrm{C}$ as initial temperature, and the calculated shear heating parameter $\left(\eta_{\mathrm{SH}}\right)$ on a logarithmic scale is reported. The shear heating

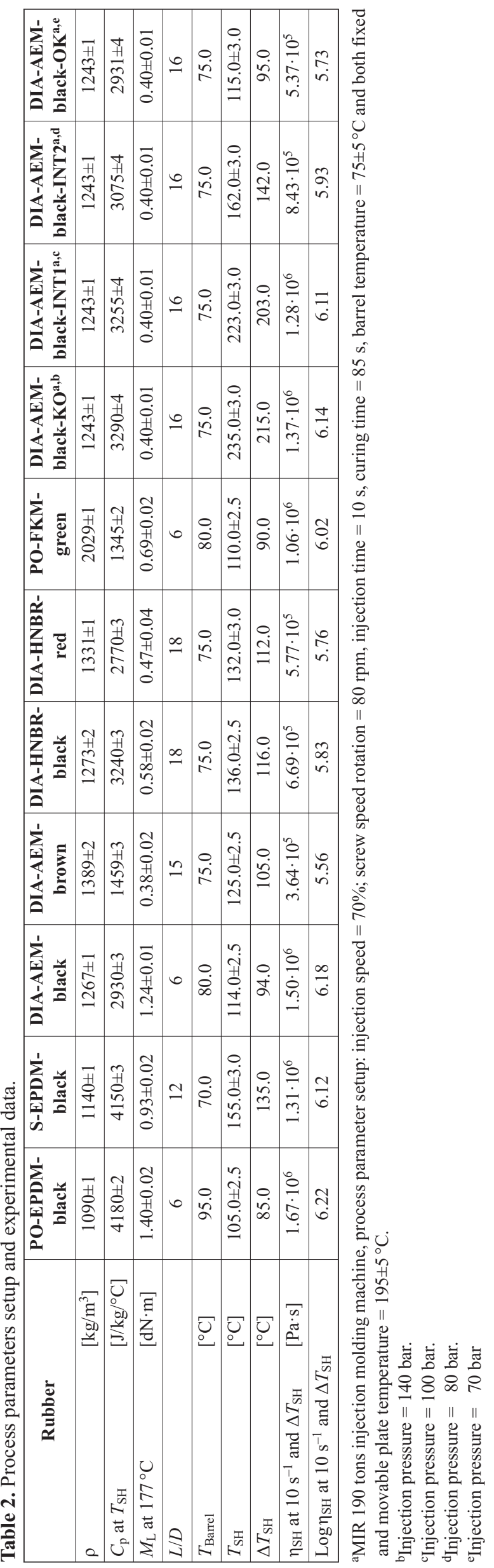


parameter was calculated using Equation (1), where the flow rate parameter $v\left[\mathrm{~s}^{-1}\right]$ is directly related to shear rate. Therefore, a conventional value of flow rate of $10 \mathrm{~s}^{-1}$ was chosen based on the commonly achievable order of magnitude of shear rate in the plasticizing extruder of the injection molding machine.

Figure 2 shows the curing curve for each rubber compound performed for 12 minutes at $177^{\circ} \mathrm{C}$ by MDR according to ASTM D5289-95. The $M_{\mathrm{L}}$ values reported in Table 2 were obtained from these curves as the minimum torque values reached after the initial transient stage. It is worth pointing out that curing curves show large differences among rubber compounds in terms of rheological and curing behavior. Once again, this heterogeneity is intentionally sought to develop a robust correlation (the roadmap) with a phenomenological approach.

The curing curves were measured on standard samples collected from the same rubber compounds used for the processing investigation. Furthermore, the selected rubber compounds were fresh material within their shelf life, where the measured $M_{\mathrm{L}}$ and the calculated shear heating parameter are subject to negligible variation.

Figure 3 shows an example of the thermal images taken of the rubber as it emerged from the reciprocating screw nozzle outlet, from which $T_{\mathrm{SH}}$ values reported in Table 2 were obtained.

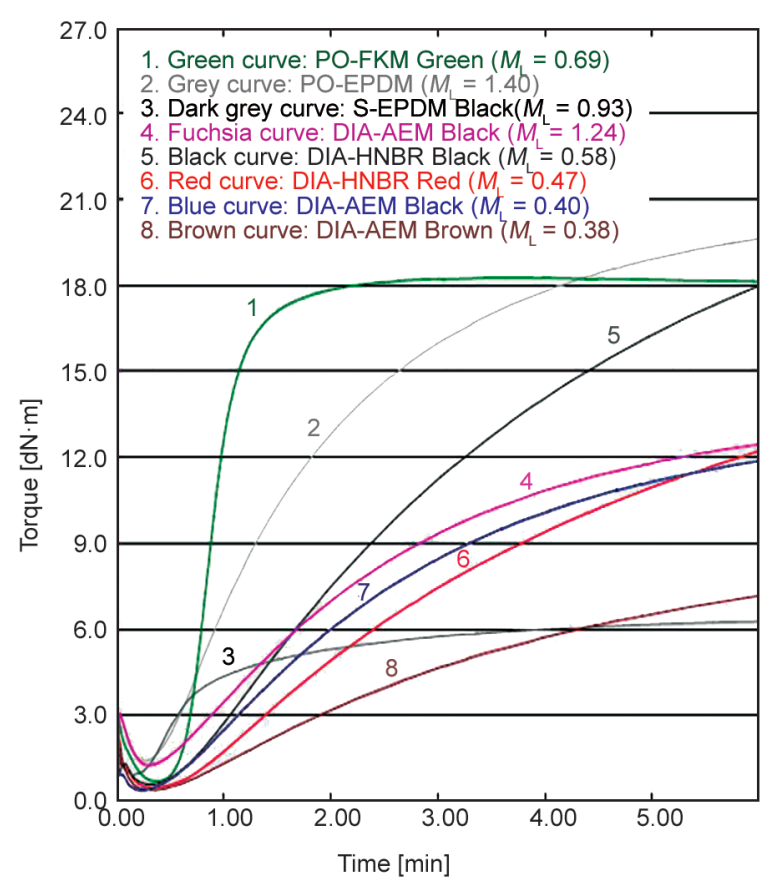

Figure 2. Vulcanization curves performed for 12 minutes at $177^{\circ} \mathrm{C}$ by $\mathrm{MDR}$.

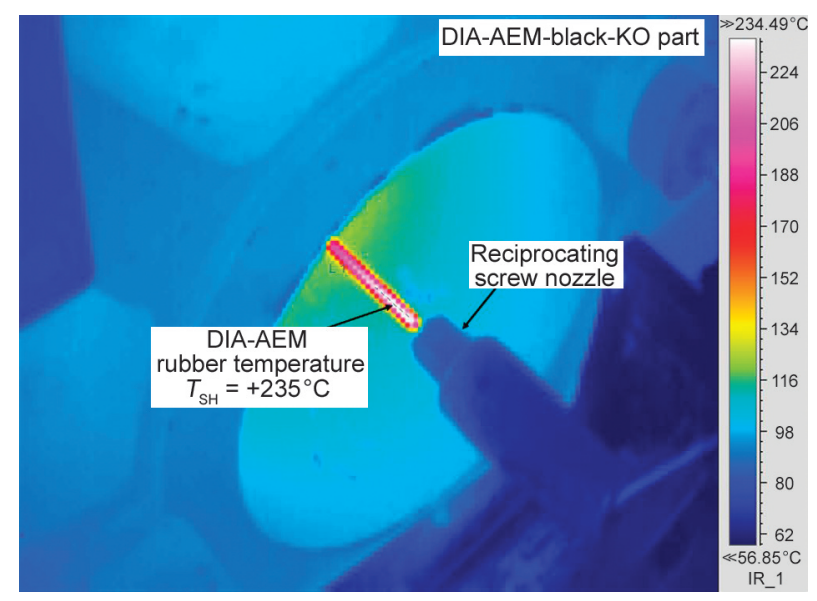

Figure 3. Image of KO run for DIA-AEM black rubber emerging from the reciprocating screw nozzle outlet.

In order to use the $\log \eta_{\mathrm{SH}}$ parameter as a tool for improvement of process control, data from different rubber compounds and production runs were compared and correlated with $M_{\mathrm{L}}$ values, thus obtaining a common correlation, a sort of roadmap.

Figure 4 shows the relationship between $\log \eta_{S H}$ at $10 \mathrm{~s}^{-1}$ and $M_{\mathrm{L}}$ from $12 \mathrm{~min}$ at $177^{\circ} \mathrm{C}$ by MDR, giving a comparison between the eight rubber compounds investigated and the eight industrial production runs with long process stability without the relevant quality issue of final parts, including the DIAAEM-black-OK run.

A proportional trend was observed with $R^{2}$ of 0.935 according to a power regression law. Therefore, a good correlation was established between the results of the laboratory test, $M_{\mathrm{L}}$, and the technological parameter $\left(\eta_{\mathrm{SH}}\right)$. The advantage of also monitoring the $\eta_{\mathrm{SH}}$ parameter is that it takes into account both rubber composition effects and the effect of operating conditions, thus providing information about the thermal history of the rubber injection and process safety. A similar correlation curve was previously shown by the authors [4] for three rubber systems (POFKM-green, PO-EPDM-black, and S-EPDM-black). In the present work, the previous investigation was extended, and further rubber systems were investigated to obtain the correlation in Figure 4. The existence of such a correlation is, therefore, confirmed and strengthened by the new data. The eight industrial production runs investigated in this work are characterized by different injection molding machines, different molded part geometries, and by very stable production runs, with very little scrap after molded part stabilization, deburring and post-cure. Therefore, the 


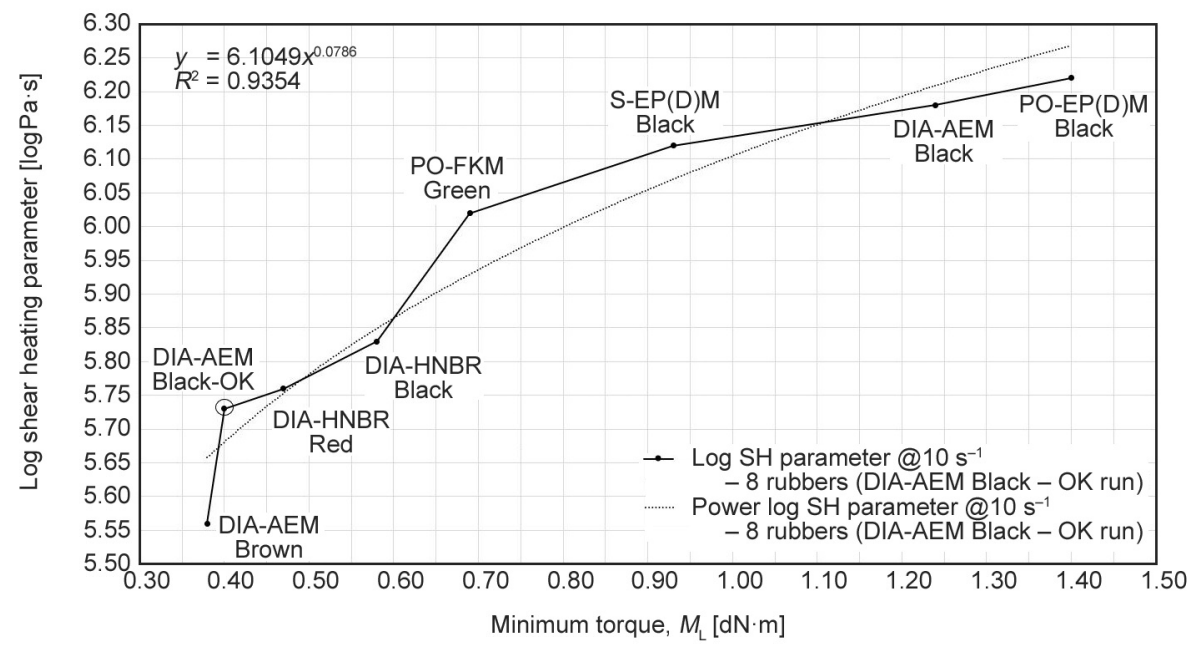

Figure 4. Relationship between shear heating parameter at $10 \mathrm{~s}^{-1}$ and minimum torque $M_{\mathrm{L}}$, comparison between 8 rubbers and 8 production runs having long process stability.

values of $\log \eta_{\mathrm{SH}}$ and $M_{\mathrm{L}}$ represent the reference points to achieve a robust correlation with the molding function to support, by an operating roadmap, the process engineer and plant operator in the improvement of the process control by online thermal measurements.

With the aim of showing the industrial application of this roadmap as a 'calibration curve' for the fast control of successful setting up of process parameters, the process optimization of AEM rubber parts affected by scorch problems and thermal degradation due to plasticizer loss is reported as follows.

The image in Figure 3 was taken during a DIAAEM-black-KO production run, in which about 450000 parts were produced. This production run was chosen as a case study for this work to show how the proposed approach helps to improve the process control of rubber injection molding. An average rubber surface temperature of $235^{\circ} \mathrm{C}$ was measured during the daily process control and, after injection molding, stabilization, deburring, and postcure of 4 hours at $175^{\circ} \mathrm{C}$, some surface cracked parts were obtained ( 8 cracked parts/1000 sampled parts). These AEM cracked parts were detected during the automatic sorting control, and they are characterized by IRHD M hardness values of 25-30 points higher than the required level, thus very out of specification. Furthermore, AEM hardened parts (12 hardened parts/1000 sampled parts) were detected, characterized by both hardness and compression-set values out of the required specification, even if less than the cracked parts. From laboratory characterization of both cracked parts and in-specification parts, cracked parts clearly showed higher hardness (+30 IRHD M points) than the standard, higher $T_{\mathrm{g}}\left(+9^{\circ} \mathrm{C}\right)$ from differential scanning calorimetry (see Table 4 ), and plasticizer loss from thermogravimetric analysis (TGA) and attenuated total reflection-Fourier transform infrared (ATR-FTIR) spectroscopy.

Figure 5 shows qualitative information of the ATRFTIR spectra comparison between DIA-AEM-blackOK and DIA-AEM-black-KO parts. The black spectrum shows the main absorption frequencies of the OK AEM rubber, while the red spectrum shows intensity reduction of the absorption frequencies of KO AEM rubber with the change of some peaks, mainly in the fingerprint region (from about 1500 to $500 \mathrm{~cm}^{-1}$ ). This spectral comparison indicates a very large variation of the sample composition, then quantitatively confirmed by TGA.

Figure $6 \mathrm{a}$ and $6 \mathrm{~b}$ show the TGA plots of DIA-AEMblack-OK and DIA-AEM-black-KO parts, respectively. Figure 6a shows a plasticizer content of about $4.71 \mathrm{wt} \%$, while Figure $6 \mathrm{~b}$ shows the absence of plasticizer, demonstrating plasticizer loss in the final parts.

During the injection molding, the rubber flow is laminar according to shear-thinning theory; thus a relevant shear rate can produce a high shear heating effect and, as a consequence, the rubber surface temperature $\left(T_{\mathrm{SH}}\right)$ increases. Therefore, it is hypothesized that plasticizer diffusion and evaporation started during the injection stage, caused by excessive shear heating measured at the reciprocating screw nozzle outlet, $T_{\mathrm{SH}}=235^{\circ} \mathrm{C}$ (Figure 3 ).

From preliminary process parameter fine-tuning performed on injection speed, screw rotation speed, and barrel temperature, it was verified that injection 


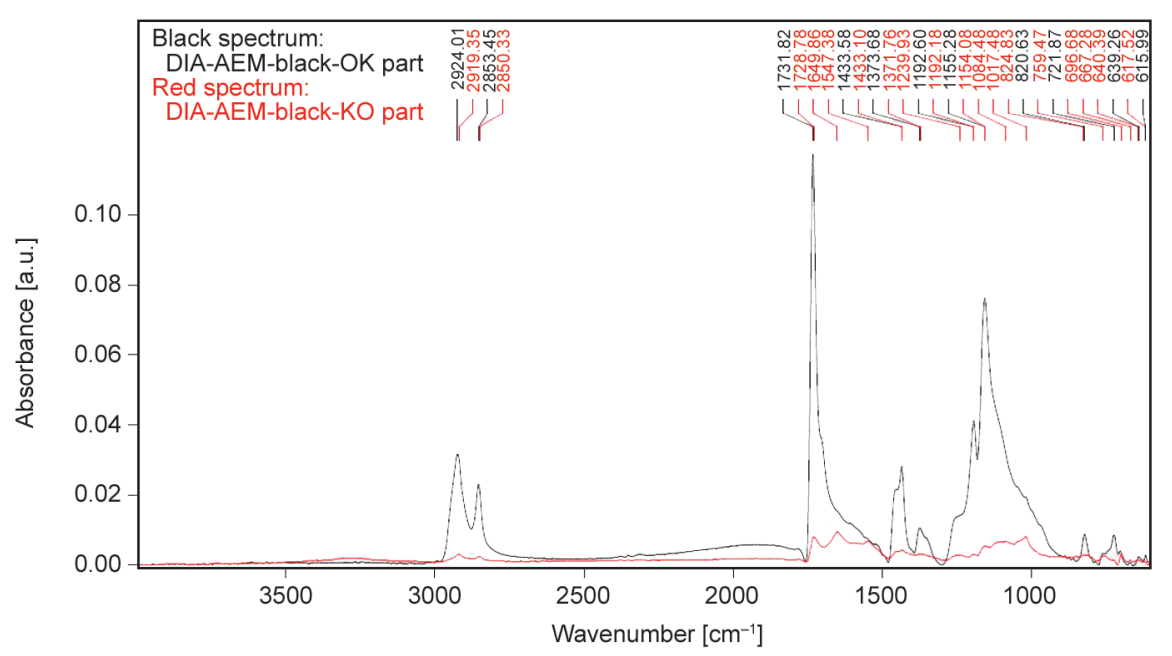

Figure 5. ATR-FTIR spectra comparison between DIA-AEM-black-OK part (black) and DIA-AEM-black-KO part (red).
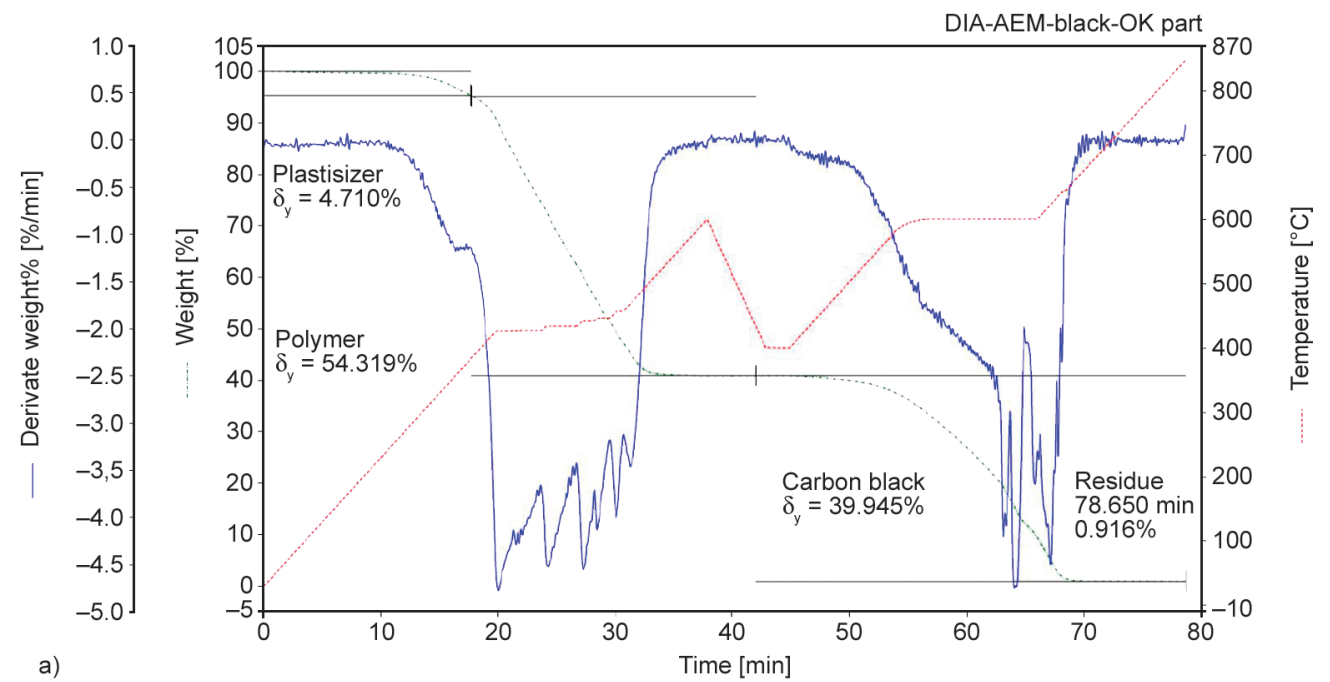

a)

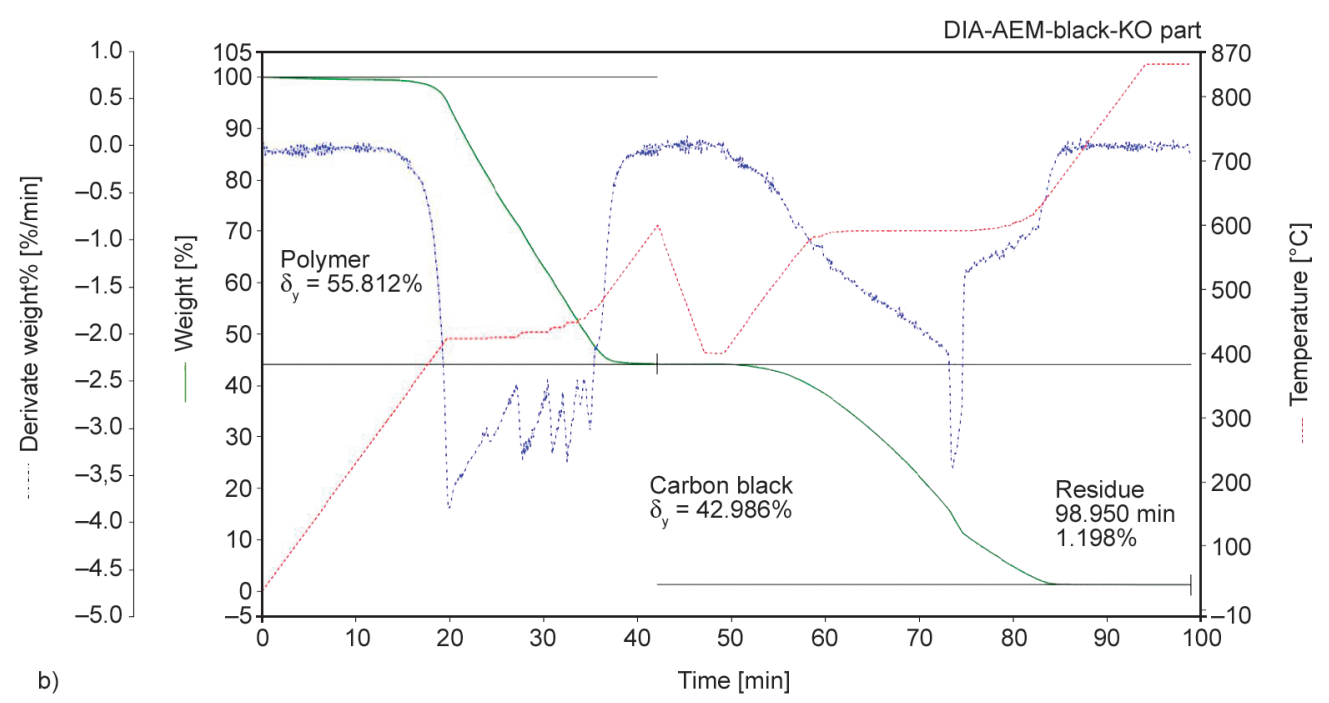

Figure 6. a) TGA plot of DIA-AEM-black-OK part. b) TGA plot of DIA-AEM-black-KO part.

pressure is the process parameter that mostly reduced this excessive shear heating.

Table 3 reports the investigated injection pressure setup $\left(P_{\mathrm{i}}\right)$ for DIA-AEM-black production runs.
Each selected injection pressure setup was maintained constant for the whole production lot of about 450000 parts. Four production runs were investigated: KO run, INT1 run, INT2 run and OK run, where 
Table 3. Injection pressure setup for DIA-AEM-black production runs.

\begin{tabular}{|l|c|}
\hline DIA-AEM-black & $\begin{array}{c}\text { Production run injection pressure } \\
\text { [bar] }\end{array}$ \\
\hline KO run & 140 \\
\hline INT1 run & 100 \\
\hline INT2 run & 80 \\
\hline OK run & 70 \\
\hline
\end{tabular}

aMIR 190 tons injection molding machine process parameter setup: injection speed $=70 \%$; screw rotation speed $=80 \mathrm{rpm}$, injection time $=10 \mathrm{~s}$, cure time $=85 \mathrm{~s}$, barrel temperature $=75^{\circ} \mathrm{C}$ and both fixed and movable plate temperature $=195^{\circ} \mathrm{C}$.

the process parameters other than injection pressure were maintained constant.

Figure 7 shows the relationship between the measured temperature, $T_{\mathrm{SH}}$, of rubber shear heating by thermal camera and the injection pressure setup, $P_{\mathrm{i}}$. Clearly, a reduction of injection pressure decreased the shear heating effect during the injection stage, maintaining the AEM rubber in a thermal condition away from high temperatures likely to produce plasticizer diffusion and evaporation.

$T_{\mathrm{SH}}$ is already a very useful parameter to guarantee very fast online process control, that is, to collect information concerning the risk of scorching and thermal degradation, leading, for example, to the diffusion of compound ingredients (low volatile chemicals), stickiness, and mold fouling, and also color variation. However, $T_{\mathrm{SH}}$ values obtained for different rubber compounds cannot be directly compared since each material has different thermal behavior.

Therefore, $\log \eta_{\mathrm{SH}}$ was introduced to allow the comparison of process outputs between DIA-AEM-black and the other materials.

Figure 8 shows the relationship between the log of the shear heating parameter at $10 \mathrm{~s}^{-1}, \log \eta_{\mathrm{SH}}$, and injection pressure setup, $P_{\mathrm{i}}$. $\log \eta_{\mathrm{SH}}$ at $10 \mathrm{~s}^{-1}$ was calculated by using the data for $\Delta T_{\mathrm{SH}}\left[{ }^{\circ} \mathrm{C}\right], \rho\left[\mathrm{kg} / \mathrm{m}^{3}\right]$,

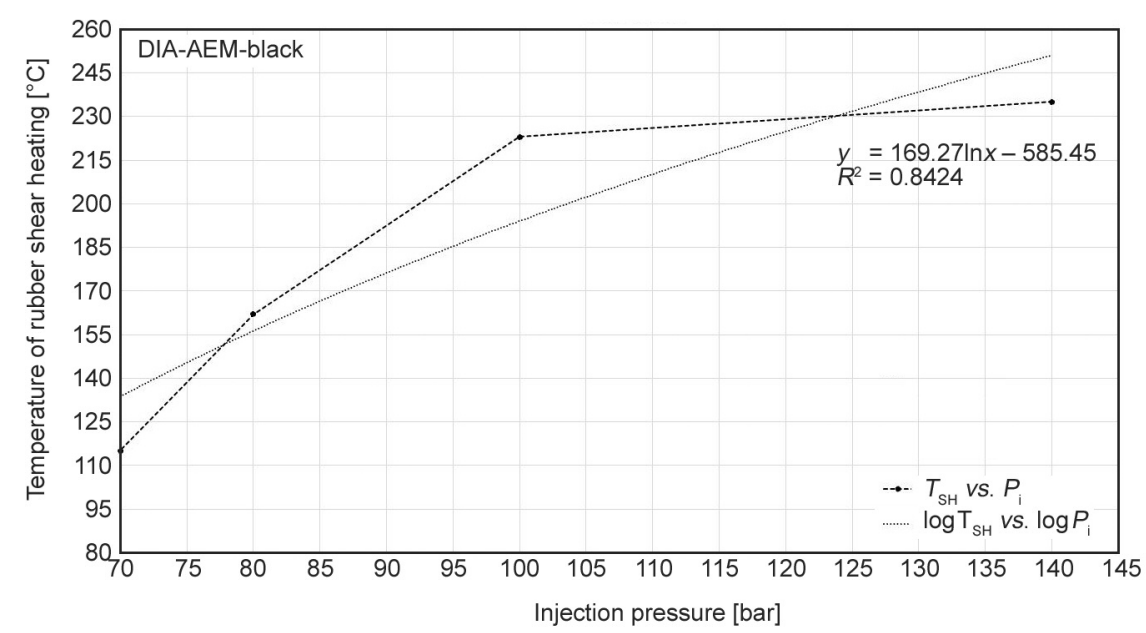

Figure 7. Relationship between temperature of rubber shear heating $T_{\mathrm{SH}}$ and injection pressure $P_{\mathrm{i}}$ for DIA-AEM-black production runs.

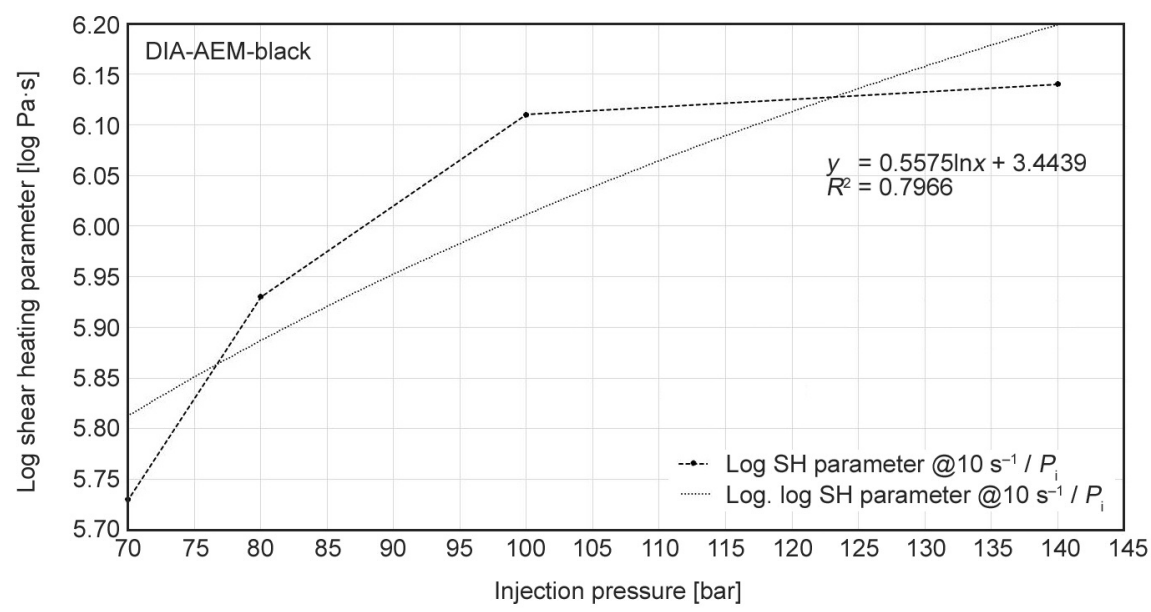

Figure 8. Relationship between $\log$ shear heating parameter at $10 \mathrm{~s}^{-1}, \log \eta_{\mathrm{SH}}$ and injection pressure $P_{\mathrm{i}}$ for DIA-AEM-black production runs. 
$C_{\mathrm{p}}[\mathrm{J} / \mathrm{kg} / \mathrm{K}]$, and $L / D$ reported in Table 2. Therefore, working with injection pressure setup of 140 bar and the DIA-AEM-black-KO run, an average $T_{\mathrm{SH}}$ of $235^{\circ} \mathrm{C}$ was measured online, and a $\log \eta_{\mathrm{SH}}$ at $10 \mathrm{~s}^{-1}$ of $6.14 \mathrm{~Pa} \cdot \mathrm{s}$ was calculated.

In this production run, eight cracked parts and 12 hardened parts in 1000 sampled parts were collected. As mentioned previously, the cracked parts showed an average hardness value of 87.0 IRHD $M$ according to ISO 48 due to plasticizer evaporation, thus about $30 I R H D$ points more than the required specification of $60 \pm 5$ (molded parts had low thickness; therefore IRHD $M$ hardness was used instead of Shore A). The hardened parts showed an average hardness value of 71.0 IRHD $M$, thus also out of specification, and compression set of $55.0 \%$, performed for 94 hours at $150^{\circ} \mathrm{C}$ after post-cure of 4 hours at $175^{\circ} \mathrm{C}$. Hence, the compression set was also out of the required specification of $\leq 50.0 \%$, according to PV3330 (Table 4).

On the contrary, working with injection pressure setup of 70 bar and the DIA-AEM-black-OK run, a lower rubber shear heating temperature was measured online, average $T_{\mathrm{SH}}$ of $115^{\circ} \mathrm{C}$, and a lower shear heating parameter was calculated, $\log \eta_{\mathrm{SH}}$ at $10 \mathrm{~s}^{-1}$ of $5.73 \mathrm{~Pa} \cdot \mathrm{s}$. Therefore, this production run guaranteed a thermal condition away from high temperatures likely to produce plasticizer diffusion and evaporation. Table 4 also reports the hardness and compression set results for the DIA-AEM-black-OK run, where average values of 58.0 IRHD $M$ and $40.0 \%$, respectively, are reported, both within the required specification.

With the aim of showing the use of the roadmap for fast control of successful setup of process parameters, Figure 9 shows the relationship between $\log \eta_{\mathrm{SH}}$ at $10 \mathrm{~s}^{-1}$ and $M_{\mathrm{L}}$ from $12 \mathrm{~min}$ at $177^{\circ} \mathrm{C}$ by MDR for the seven rubber compounds with very stable industrial production runs and DIA-AEM-black-KO run $\left(R^{2}\right.$ of 0.526$)$, DIA-AEM-black-INT1 run $\left(R^{2}\right.$ of $0.562)$ and DIA-AEM-black-INT2 run $\left(R^{2}\right.$ of 0.788$)$. In more detail, new curves were created, starting from the roadmap reported in Figure 4, by replacing the data of DIA-AEM-black-OK with values of either DIA-AEM-black-KO run (Figure 9a), INT1 run (Figure 9b) or INT2 run (Figure 9c), while keeping the values of the other seven productions runs constantly. Only the $\log \eta_{\mathrm{SH}}$ values of DIA-AEM-black were modified, whereas $M_{\mathrm{L}}$ was always the same since it is a laboratory property, not influenced by process parameters.

By introducing the curves of the KO run, INT1 run, and INT2 run, some relevant deviations from the previous proportional trend were observed, especially in Figure 9a (red curve) with $R^{2}$ of 0.526 according to the power regression model. Accordingly, the DIA-AEM-black-KO run, based on injection pressure setup of $140 \mathrm{bar}$, average $T_{\mathrm{SH}}$ of $235^{\circ} \mathrm{C}$, and $\log \eta_{\mathrm{SH}}$ at $10 \mathrm{~s}^{-1}$ of $6.14 \mathrm{~Pa} \cdot \mathrm{s}$, did not allow a stable production cycle, where hardened and cracked parts were produced. Furthermore, DIA-AEM-black-INT1 and INT2 runs were used to fine-tune the injection pressure setup from $\mathrm{KO}$ to $\mathrm{OK}$ runs, thus in this case also the $\log \eta_{\mathrm{SH}}$ at $10 \mathrm{~s}^{-1}$ values deviated from the proportional trend with $R^{2}$ of 0.562 and 0.788 , respectively. Finally, the DIA-AEM-black-OK run, based on injection pressure setup of $70 \mathrm{bar}$, average $T_{\mathrm{SH}}$ of $115^{\circ} \mathrm{C}$, and $\log \eta_{\mathrm{SH}}$ at $10 \mathrm{~s}^{-1}$ of $5.73 \mathrm{~Pa} \cdot \mathrm{s}$, allowed a very stable production cycle without hardened and cracked parts. In this process setup, the $\log \eta_{\mathrm{SH}}$ value was within the proportional trend with $R^{2}$ of 0.935 according to the power regression model (see Figure 4). Therefore, the coefficient of determination of $\log \eta_{\mathrm{SH}} v s M_{\mathrm{L}}$ curves provides a good indication of process stability of DIA-AEMblack runs.

Figure 4 and Figure 9 clearly show how $\log \eta_{\mathrm{SH}}$ values of a production run, combined with $M_{\mathrm{L}}$ values, give indication of the successful output of the injection molding process by comparison of this data with a well-established roadmap obtained from stable production runs of different rubber compounds and process conditions. This monitoring has the advantage of being fast, and provides information about the stability of the process while it is running, well before completing the production run.

Table 4. Physical-mechanical data for DIA-AEM-Black, comparison between OK and KO runs.

\begin{tabular}{|c|c|c|}
\hline Parameter $^{\mathrm{a}}$ & DIA-AEM-black-OK & DIA-AEM-black-KO \\
\hline Hardness after post-cure $4 \mathrm{hrs}$. at $175^{\circ} \mathrm{C}, \mathrm{IRHD} \mathrm{M}$ & 58.0 & 71.0 \\
\hline Compression set $\left(94 \mathrm{hrs}\right.$. at $\left.150^{\circ} \mathrm{C}\right)$ after post-cure $4 \mathrm{hrs}$. at $175^{\circ} \mathrm{C} \quad[\%]$ & 40.0 & 55.0 \\
\hline Glass transition temperature (DSC), $T_{\mathrm{g}}$ & -35.7 & -26.7 \\
\hline
\end{tabular}

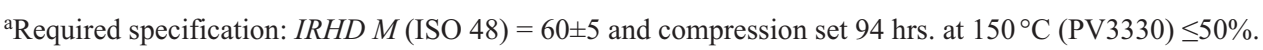



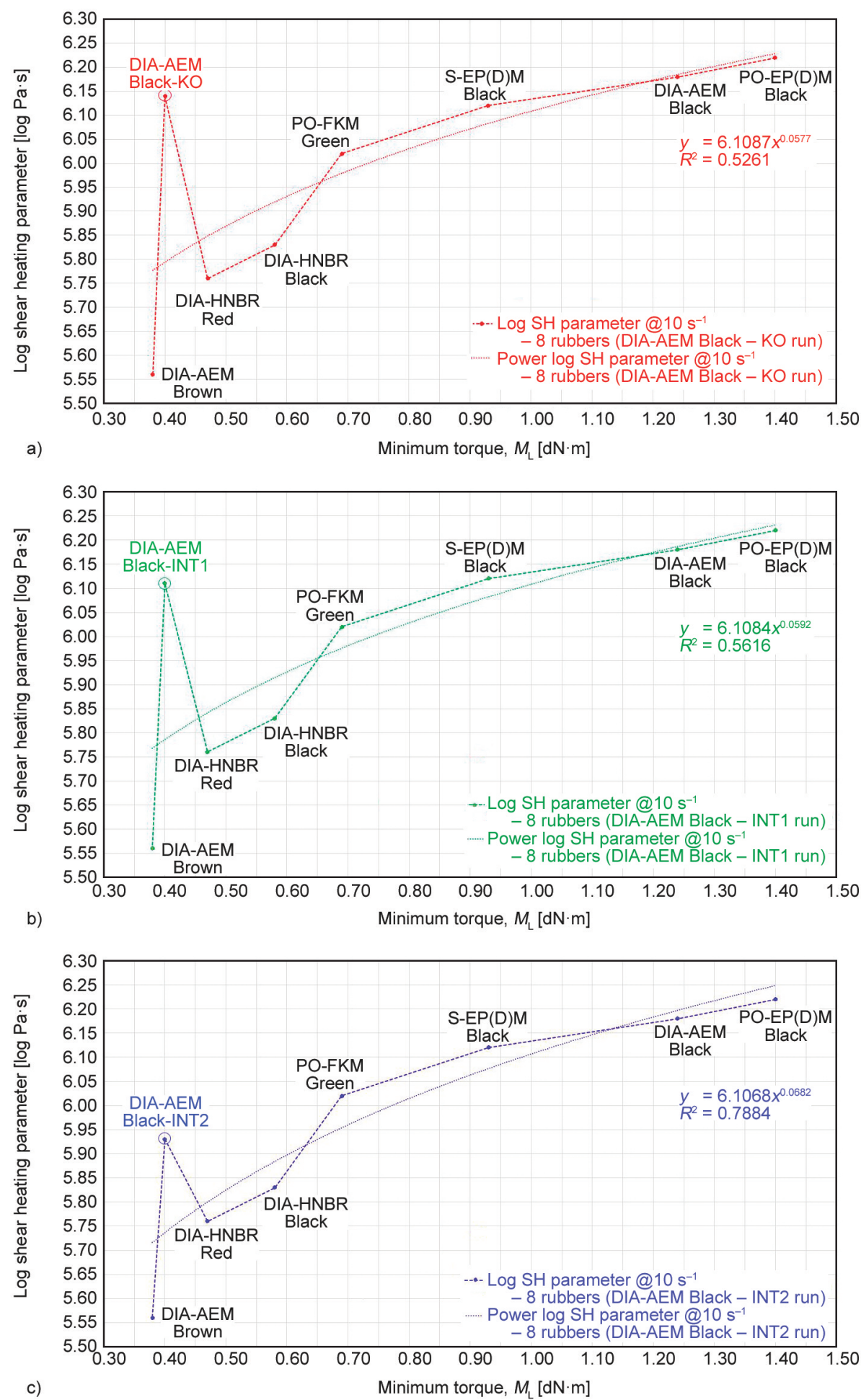

Figure 9. a) Relationship between shear heating parameter at $10 \mathrm{~s}^{-1}$ and minimum torque $M_{\mathrm{L}}$, comparison between 7 rubber compounds with very stable production runs and DIA-AEM-black-KO run. b) Relationship between shear heating parameter at $10 \mathrm{~s}^{-1}$ and minimum torque $M_{\mathrm{L}}$, comparison between 7 rubber compounds with very stable production runs and DIA-AEM-black-INT1 run. c) Relationship between shear heating parameter at $10 \mathrm{~s}^{-1}$ and minimum torque $M_{\mathrm{L}}$, comparison between 7 rubber compounds with very stable production runs and DIA-AEM-black-INT2 run.

The proposed approach, obtained for a very heterogeneous sample of rubber compounds and operating conditions, was found to be successful and useful. It is worth pointing out that the roadmap in the present work was obtained for rubber compounds having similar hardness. In principle, it is possible to extend this approach to other types of rubber compounds, but the limits of validity of the roadmap still need to 
be investigated. In the meantime, to apply it to a new rubber compound, preliminary tests in good operating conditions must be performed to demonstrate that the new data are in accordance to the established operating roadmap.

\section{Conclusions}

This study aimed to improve the process control for optimal injection molding of technical rubber parts by introducing a new tool for online monitoring of the shear heating phenomenon. Specifically, very fast process control of injection molding is proposed and applied to an industrial case study to improve the processing behavior of AEM with a focus on its scorch and thermal degradation issues. The online monitoring is based on direct measurement of the surface rubber temperature $\left(T_{\mathrm{SH}}\right)$ by an infrared thermal camera at the nozzle outlet of the injection molding machine extruder. This measure provides very fast online process control and provides information about rubber behavior and its shear heating effect before injection of the rubber into the mold cavities. This measured temperature led to the calculation of a technological parameter designated shear heating parameter, $\eta_{\mathrm{SH}}$, which also takes into account physical material properties (density and specific heat capacity) and process conditions $(L / D$ ratio).

Eight different rubber compounds based on AEM, HNBR, FKM, and EP(D)M elastomers were tested. In particular, eight rubber compounds and eight industrial production runs with long process stability and various production runs of DIA-AEM-black, where stable, unstable, and also the intermediate production runs were investigated. The results of $\eta_{\mathrm{SH}}$ were correlated with $M_{\mathrm{L}}$ from MDR laboratory measurements. The relationship between $\log \eta_{\mathrm{SH}}$ and $M_{\mathrm{L}}$ for the 8 rubber compounds with long process stability, including the DIA-AEM-black-OK run, showed a proportional trend, with $R^{2}$ of 0.935 according to the power regression model. Thus, this proportional trend represented a reference point to achieve a robust correlation with the molding function to support, by an operating roadmap, the process engineer and plant operator in the improvement of the process control by thermal online measurements. The operating roadmap was successfully used to improve the process control of industrial productions based on
AEM rubber compounds affected by scorch problems and thermal degradation due to plasticizer loss. The results show that the shear heating parameter is a very suitable tool because it considers not only the rubber compositional effects based on density and specific heat capacity measurements but also the effect of operating conditions setup, especially based on $T_{\mathrm{SH}}$ online measurements. The $\eta_{\mathrm{SH}}$ gives more information than $M_{\mathrm{L}}$ about the thermal history and process safety; thus it can be used in industrial practice to improve the process control by improving the knowledge of rubber behavior and its shear heating effect during the injection stage. Therefore, this knowledge can help the process engineer, plant operator, and mold designer to:

i) provide suitable process parameter setup and mold design to avoid scorch problems and thermal degradation, preventing the production of out of specification rubber parts;

ii) optimize processes for new materials where information about thermal behavior is lacking because, differently from $T_{\mathrm{SH}}, \log \eta_{\mathrm{SH}}$ ) is able to correlate data obtained from different rubber compounds;

iii) select the injection molding machine, taking into account the rubber compound rheological behavior.

In this article, the operating roadmap based on two technological parameters, $\eta_{\mathrm{SH}}$ and $M_{\mathrm{L}}$, is proposed as a new tool very suitable for industrial practice. However, some insights concerning its physical meaning and further applications still need to be explored. Therefore, further investigations will be carried out to study its relationship with $\alpha$, such as the effects of nozzle type, $L / D$ of nozzle, and residence time. Finally, the possibility to use the shear heating parameter in the setup of computer-aided engineering simulations useful for mold design and injection molding process optimization can also be investigated.

\section{Acknowledgements}

This paper is the result of a collaboration created by Italian Gasket S.p.A and the Department of Mechanical and Industrial Engineering of the University of Brescia. The rubber compound characterization and the processing tests were performed in the Italian plant of Italian Gasket. The authors wish to thank Germana Bergomi, board member of Italian Gasket, for starting the collaboration between Italian Gasket S.p.A and the University of Brescia. 


\section{References}

[1] Stanek M., Manas D., Manas M., Ovsik M., Senkerik V., Skrobak A.: Injection molding of rubber compound influenced by injection mold surface roughness. Advanced Materials Research, 1025-1026, 283-287 (2014). https://doi.org/10.4028/www.scientific.net/AMR.1025-1026. 283

[2] Proske M., Bhogesra H.: Evaluating the root causes of rubber molding defects through virtual molding. Rubber World, 255, 20-26 (2016).

[3] Long H.: Basic compounding and processing of rubber. Rubber Division of the ACS, Akron (1985).

[4] Ramini M., Agnelli S.: Shear heating parameter of rubber compounds useful for process control in injection molding machine. Rubber Chemistry and Technology, 93, 729-737 (2020). https://doi.org/10.5254/rct.20.79954

[5] Nakashima K., Fukuta H., Mineki M.: Anisotropic shrinkage of injection-molded rubber. Journal of Applied Polymer Science, 17, 769-778 (1973). https://doi.org/10.1002/app.1973.070170309

[6] Nishizawa H.: Heat controls and rubber flow behaviour in screw of extruder and injection machine and the problems occurring in these processes. International Polymer Science and Technology, 43, 41-50 (2016). https://doi.org/10.1177/0307174X1604300409

[7] Stritzke B.: Custom molding of thermoset elastomers a comprehensive approach to materials, mold design, and processing. Hanser, Munich (2009).

[8] Cox H. W., Macosko C. W.: Viscous dissipation in die flows. AIChE Journal, 20, 785-795 (1974). https://doi.org/10.1002/aic.690200421

[9] Winter H. H.: Temperature fields in extruder dies with circular, annular, or slit cross- section. Polymer Engineering and Science, 15, 84-89 (1975). https://doi.org/10.1002/pen.760150206

[10] Tadmor Z., Gogos C. G.: Principles of polymer engineering. Wiley, Hoboken (2006).

[11] Ramini M., Viola G. T., Paganin L., Battisti M.: Achieving savings in the post-curing process of fluoroelastomer compounds prepared by injection molding. Rubber World, 261, 46-51 (2019).

[12] Traintinger M., Kerschbaumer C., Lechner B., Friesenbichler W., Lucyshyn T.: Temperature profile in rubber injection molding: Application of a recently developed testing method to improve the process simulation and calculation of curing kinetics. Polymers, 13, 380 (2021). https://doi.org/10.3390/polym13030380

[13] McBride E.: Press cure and post cure options for AEM terpolymers. in ' $174^{\text {th }}$ Fall Technical Meeting of the Rubber Division, American Chemical Society 2008, Louisville, USA' 86 (2008).
[14] McBride E.: Processing of AEM compounds: Scorch issues. in ' $194^{\text {th }}$ Fall Technical Meeting of the Rubber Division, American Chemical Society 2018, Louisville, USA' 1289 (2018).

[15] McBride E.: Processing of AEM compounds: Scorch issues. Rubber World, 256, 32-38 (2019).

[16] Öztürk S., Cömez E. E., Hoşgün H. L.: The rheological, mechanical and aging properties of AEM/EPDM rubber blends. Journal of Rubber Research, 24, 61-67 (2021). https://doi.org/10.1007/s42464-020-00073-5

[17] Brown R.: Physical test methods for elastomers. Springer, New York (2018).

[18] Vera-Sorroche J., Kelly A. L., Brown E. C., Coates P. D.: Infrared melt temperature measurement of single screw extrusion. Polymer Engineering and Science, 55, 10591066 (2015).

https://doi.org/10.1002/pen.23976

[19] Straka K., Praher B., Hettrich-Keller M., Steinbichler G.: To the measurement and influences of process parameters variations on the axial melt temperature profile in the screw chamber of an injection molding machine. in 'SPE ANTEC 2017, Anaheim, USA, 1645-1651 (2017).

[20] Ageyeva T., Horváth S., Kovács J. G.: In-mold sensors for injection molding: On the way to industry 4.0. Sensors, 19, 3551 (2019).

https://doi.org/10.3390/s19163551

[21] Farahani S., Brown N., Loftis J., Krick C., Pichl F., Vaculik R., Pilla S.: Evaluation of in-mold sensors and machine data towards enhancing product quality and process monitoring via Industry 4.0. International Journal of Advanced Manufacturing Technology, 105, 13711389 (2019). https://doi.org/10.1007/s00170-019-04323-8

[22] Chen J-Y., Tseng C-C., Huang M-S.: Quality indexes design for online monitoring polymer injection molding. Advances in Polymer Technology, 2019, 3720127 (2019). https://doi.org/10.1155/2019/3720127

[23] Zhang N., Gilchrist M. D.: Characterization of thermorheological behavior of polymer melts during the micro injection moulding process. Polymer Testing Journal, 31, 748-758 (2012). https://doi.org/10.1016/j.polymertesting.2012.04.012

[24] Ramini M., Agnelli S.: Process control in injection molding machine by using shear heating parameter of rubber compounds, All about rubber compounding, May 6 2021, (virtual event), knowhow webinars forum by Technobiz. 